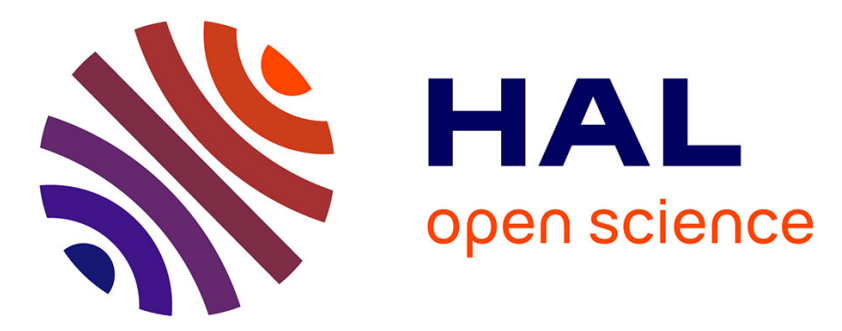

\title{
Multi-party Interactive Visioneering Workshop for Smart Connected Products in Global Manufacturing Industry Considering PLM
}

\author{
Satoshi Goto, Elio Trolio, Osamu Yoshie, Kin’ya Tamaki
}

\section{To cite this version:}

Satoshi Goto, Elio Trolio, Osamu Yoshie, Kin'ya Tamaki. Multi-party Interactive Visioneering Workshop for Smart Connected Products in Global Manufacturing Industry Considering PLM. 13th IFIP International Conference on Product Lifecycle Management (PLM), Jul 2016, Columbia, SC, United States. pp.501-511, 10.1007/978-3-319-54660-5_45 . hal-01699733

\section{HAL Id: hal-01699733 \\ https://hal.inria.fr/hal-01699733}

Submitted on 2 Feb 2018

HAL is a multi-disciplinary open access archive for the deposit and dissemination of scientific research documents, whether they are published or not. The documents may come from teaching and research institutions in France or abroad, or from public or private research centers.
L'archive ouverte pluridisciplinaire HAL, est destinée au dépôt et à la diffusion de documents scientifiques de niveau recherche, publiés ou non, émanant des établissements d'enseignement et de recherche français ou étrangers, des laboratoires publics ou privés. 


\title{
Multi-party Interactive Visioneering Workshop for Smart Connected Products in Global Manufacturing Industry Considering PLM
}

\author{
Satoshi Goto ${ }^{1,3,4}$, Elio Trolio ${ }^{2}$, Osamu Yoshie ${ }^{3}$, and Kin'ya Tamaki ${ }^{4}$ \\ ${ }^{1}$ Business Transformation Management, PTC Japan Co. Ltd., Japan \\ ${ }^{2}$ IoT Strategy \& Business Consulting, ThingWorx Inc., U.S.A. \\ ${ }^{3}$ Graduate School of Information, Production and Systems, Waseda University, Japan \\ ${ }^{4}$ Human Innovation Research Center, Aoyama Gakuin University, Japan \\ sgoto@ptc.com, elio.trolio@thingworx.com,yoshie@waseda.jp,kinya.tamaki@gmail.com
}

\begin{abstract}
Currently, Internet of Things (IoT) is a dominant technology and a core mechanism for the third Information Technology (IT) revolution. Many benefits are expected to be enabled by implementing the IoT technologies through the product lifecycle management (PLM) process, such as remote monitoring of field service and predictive quality reliability engineering design in R\&D. Smart connected products (SCPs) are forecast to produce tremendous business value. However, significant business challenges are associated with SCPs. Manufacturers have difficulty in rapidly launching IoT products in the market. This paper proposes a pragmatic visioneering workshop framework informed by real-world industry practices. The group facilitation for visioneering focuses on identifying the relation between the 26 practical IoT use cases through the PLM process. Moreover, the proposed workshop format will also enable the participants to engage in a discussion and interact with the framework through use case analysis.
\end{abstract}

Keywords: Internet of Things (IoT), PLM Process, Smart Connected Products (SCPs), Multi-Party Interaction, Visioneering Workshop Facilitation

\section{Introduction}

Currently, Internet of Things (IoT) is a dominant technology and is called the third information technology (IT) revolution [7]. The IoT technology enables multiple opportunities and business values through the entire product life cycle management (PLM) process [12]. Remote monitoring of field service and predictive quality reliability engineering design in R\&D. Smart factories are alone valuated as a $\$ 3.7$ trillion dollar industry and are forecast to produce tremendous business value [5]. It is estimated that 30 billion connected "things" will exist by 2020 [4].

Global discrete manufacturing companies such as automotive and high-tech electronics and industrial equipment manufacturers are currently facing significant IoT related business challenges. It is very difficult for these companies to rapidly launch IoT products in the market because of the new complexity derived from the 
addition of software applications and connectivity components. According to the results of IDC research, it was found that $66 \%$ of the discrete manufacturers pursue IoT initiatives and $40 \%$ of them are still at the pilot trial stage [4]. In addition, toplevel executives are faced with new strategic challenges such as identifying new corporate models to accelerate the investment in R\&D. Moreover, they are still struggling to get started. The PLM experts who are assigned the task of IoT promotion in such companies have various individual opinions and pursue different directions. This causes difficulties in choosing a single direction and achieving consensus regarding the development of smart connected products (SCPs). Therefore, companies spend more time in the planning stage of SCPs as compared to general products. In this new era of SCP development, the first critical step is to coordinate the early stages of the PLM process. Thus, a multi-party interactive consensusbuilding approach is very important; such an approach must be rapid.

This paper proposes a pragmatic visioneering workshop framework informed by real-world industry practices. The group facilitation of visioneering focuses on identifying the relation between the key issues and challenges in some of the 26 practical IoT use cases. It identifies how a company can plan an SCP solution and craft a high-level IoT value roadmap chart understanding each phase of the PLM process. This paper also proposes to incorporate a workshop format that will enable participants to engage in a discussion and interact with the framework through customer value chain analysis (CVCA) [3] referring to the IoT use cases as a guide during the group discussion session.

The paper is organized as follows: Section 2 briefly presents the 26 IoT use cases that are categorized through the entire product lifecycle stages. Section 3 proposes a framework of IoT visioneering workshop agenda. A case study of a workshop conducted by a leading global discrete manufacturer is discussed in Section 4. We discuss whether the visioneering framework was valuable to the participants in group facilitation in the SCP concept planning phase. Finally, in Section 5, it is concluded that the workshop provided a benefit of achieving consensus in a shorter time period than that expected by the participants. Moreover, an outlook on this study is also mentioned in the conclusion of this paper.

\section{IoT Use Cases throughout Product Lifecycle Stages}

To overcome the stuck business situation described in Section 1, templates of the 26 IoT use cases have been developed $[9,10,11]$. These templates are used as a guide to help the stakeholders who seek to understand how to create a business value of SCP solutions in the early stage of product strategy planning. Each use case is defined as a typical IoT practice example that is experienced by hundreds of manufactures through the PLM processes. The 26 use cases are also categorized by six key product lifecycle stages (Table 1) so that the use cases aligned with the PLM process can be recognized.

Table 1. IoT Use Cases aligned with PLM processes [11]

Category (a.k.a. PLM process) $\quad$ IoT Use Case




\begin{tabular}{l|l}
\hline A) Marketing and Sales & 1. Customer Insights and Opportunities \\
& 2. Flexible Billing and Pricing Models \\
3. New Value Added Services
\end{tabular}

The contents of the above 26 use cases are mainly utilized at the proposed visioneering session during the group activity; the participants can clearly determine what they need to focus on for their IoT initiatives. One of the benefits is that it helps the group to quickly understand and easily choose key IoT initiatives in shorter discussion time, for example, in 15-20 min. A more specific description of this is provided in Section 3.

\section{Design of IoT Visioneering Workshop}

\subsection{Background and Aim}

This workshop is designed for product managers and lead engineers who are working at manufacturing companies. As a background, C-level executives assigned them to be as corporate led IoT product promotion members. However, the workshop members are not always available to work full-time on the assigned mission. Thus, an efficient and more productive approach is required that will enable consensus building over a shorter time. The members need to rapidly provide a single common SCP solution idea that contributes to the executives' strategic goals. This paper aims to provide a procedure for thinking through facilitated group visioneering approaches in such business situations.

\subsection{Proposed Workshop Agenda \& Timetable}


Table 2 shows the proposed agenda for the visioneering workshop for multi-party participants invited from the various product and service development organizations in the company. The timetable is very compact, and an intensive configuration for such busy participants is a necessary and sufficient condition. The workshop is designed to be completed in a total of 5 hours and is configured in 7 step-by-step sessions.

Table 2. Proposed Agenda Template for the Visioneering Workshop

\begin{tabular}{|c|c|c|c|}
\hline Round \# & Session Agenda & $\begin{array}{c}\text { Interval } \\
\text { (min.) }\end{array}$ & $\begin{array}{l}\text { Clock Time } \\
\text { (as sample) }\end{array}$ \\
\hline 1 & Introduction/Agenda Review & 15 & 13:00-13:15 \\
\hline 2 & IoT Introduction \& Strategy Overview & 30 & $13: 15-13: 45$ \\
\hline \multirow[t]{2}{*}{3} & Global Industry IoT Case Studies & 45 & $13: 45-14: 30$ \\
\hline & BreakTime & 15 & $14: 30-14: 45$ \\
\hline 4 & $\begin{array}{l}\text { Group Work for Visioneering } \\
\text { Step 1. Identify Stakeholders } \\
\text { Step 2. Select major IoT Use Cases } \\
\text { Step 3. Narrow-down Use Cases } \\
\text { Step 4. Craft IoT Value Roadmap } \\
\text { Step 5. Set Metrics for IoT Business }\end{array}$ & 120 & $14: 45-16: 45$ \\
\hline \multirow[t]{2}{*}{5} & Group Presentation & 15 & $16: 45-17: 00$ \\
\hline & Break Time & 15 & $17: 00-17: 15$ \\
\hline 6 & IoT Enablement & 30 & $17: 15-17: 45$ \\
\hline \multirow[t]{2}{*}{7} & Wrap-up/Next Steps Discussion & 15 & $17: 45-18: 00$ \\
\hline & 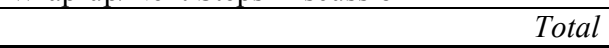 & 300 & 13:00-18:00 \\
\hline
\end{tabular}

\subsection{Preliminary Questionnaire}

A preliminary questionnaire is an efficient approach for obtaining the participant's individual thoughts and insights in advance and is employed to facilitate the smooth running of the workshop. The following is the proposed format for the questionnaire comprising two parts.

\section{Part 1: Ask for Business Strategies (Value Drivers)}

Part 1 of the questionnaire asks the questionee about Business Strategies and comprises 6 options (Fig. 1) called "Value Drivers" [9, 10, 11]. These 6 options are organized into two categories. Options 1-3 are based on "Operational Effectiveness" and are aimed at helping to improve the optimization of the operational performance. Options 4-6 are for strategic differentiation. The idea of Part 1 is based on the competitive strategy framework developed by Professor Michael Porter [6, 7].

\section{Part 2: Ask for Current States (Challenges)}

Part 2 is focused on typical common business challenges (Fig. 1). Twenty options are given that comprehensively describe the end users' problems through the entire product lifecycle process with examples such as the slow pace of product innovation and expensive internal development process for SCP projects.

\section{Web-based Assessment Tool}

The proposed preliminary questionnaire is also available as a Web-based system for the workshop participants so that they can respond to the questionnaire on the Web 
(https://jp.surveymonkey.com/r/XKQ9ZFV). The questionnaire must be submitted a couple of days prior to the date of the workshop. The option selection for Parts 1 and Part 2 is very easy for the questionee, and it normally takes 15 minutes to complete each Part. The Web system is a freeware that everyone can use on the Web [13]. An Excel sheet is also available for the participants who cannot access the internet environment (Fig. 1).

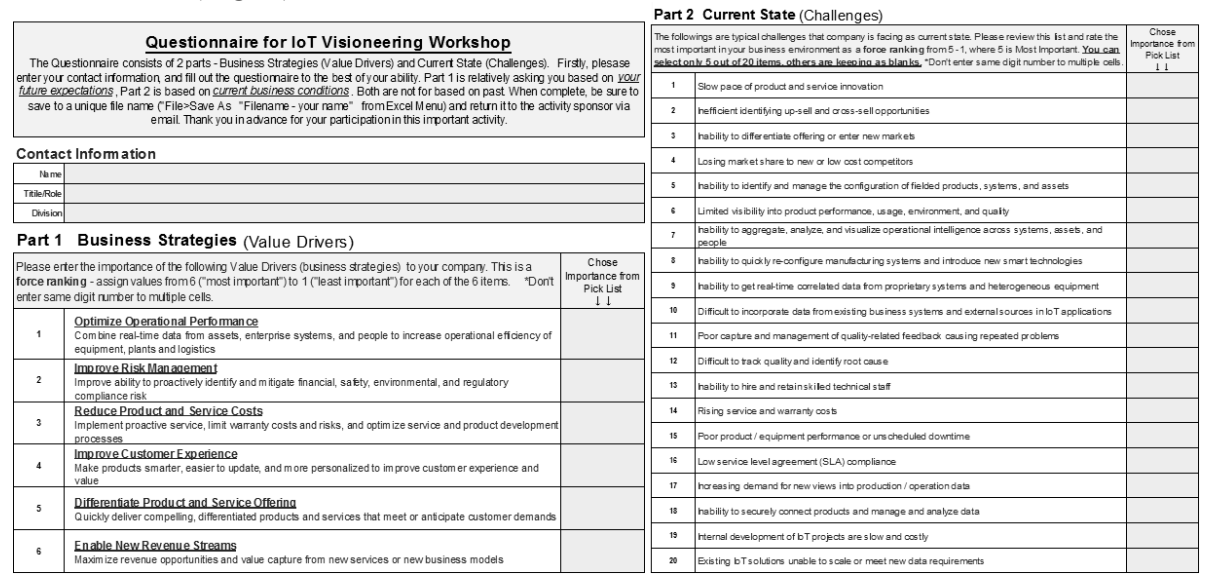

Fig. 1. Preliminary Questionnaire (Part 1 and Part 2) https://jp.surveymonkey.com/r/XKQ9ZFV

\subsection{Design of Group Facilitation for Visioneering Session}

This workshop emphasizes intensive group work (round \#4 in Table 2), wherein 4 or 5 people per group and 2 or 3 groups per workshop are reasonable. Moreover, 2 facilitators support all the group activities. During the group session, many debating situations are possible. In one case, each person has his own opinion and may try to push his own idea to others. In another roundtable, the group discussion would be very quiet and low-key; nobody tries to speak up and the participants are just watching each other until someone makes a comment. Either one of these two cases is not always ideal for building a consensus for a single direction. Furthermore, a difficulty in reaching the final goal of the group discussion outcome will be faced in both cases. Therefore, the following five pragmatic steps are proposed as an engineering facilitation methodology aiming to smoothly achieve a consensus for a single direction (Table 3).

Table 3. Five Steps for Group Facilitation at a Visioneering Session

\begin{tabular}{c|l}
\hline Step \# & Group Discussion Topic \\
\hline 1 & Identify Stakeholder-utilizing Customer Value Chain Analysis (CVCA) \\
2 & Select Top 6 IoT Use Cases - aligning with corporate Value Drivers \\
3 & Narrow-down the Use Cases - selecting 3 out of 6 for to be more specific \\
4 & Craft IoT Value Roadmap-positioning the Use Cases on the value maturity \\
5 & Set Metrics (KPIs)_qualifying Business Goals \\
\hline
\end{tabular}


Step 1: Identify Stakeholders-utilizing Customer Value Chain Analysis (CVCA) Using CVCA methodology [3], the group members are encouraged to discuss all the people and processes that impact or depend on the product or asset. First, this requires the group members to select a product or asset to focus the discussion on; the members will select and identify as many stakeholders as possible, such as internal/external and direct/indirect. The roles of the stakeholders should be specific. The discussed stakeholders should then be connected with a line. As a result, a CVCA diagram is drawn surrounding the selected product or asset. This task is aimed to help the members realize that there are many influencers and to expand the value of the product or asset connecting various stakeholders. For this step, 20 minutes is an appropriate amount of time.

Step 2: Select Top 6 IoT Use Cases-aligning with corporate Value Drivers

In the second step, the group members will review the 26 use case examples and select 6 use cases. This is to support their conclusion whether their selected product or asset will become worthwhile as a future SCP solution. In addition, they need to understand which of the selected use cases provide business impact for the specific Value Drivers (Business Strategies) based on the preliminary results of Part 1 of the questionnaire. For this step, 15 minutes is an appropriate amount of time.

Step 3: Narrow-down selected Use Cases-selecting 3 out of 6 for to be more specific

In the third step, the participants review and prioritize the above selected 6 use cases and select the top 3 use cases. Then, the members will discuss why these use cases were selected. Finally, they will unanimously agree on the most important use case for the first action on the future roadmap. For this step, 10 minutes is an appropriate amount of time.

Step 4: Craft IoT Value Roadmap-positioning the Use Cases on the value maturity The members will use the selected top 3 use cases to consider the steps and value maturity. Considering the As-Is situation and examining the result of the preliminary questionnaire, they will create an IoT Value Roadmap to add a To-Be objective and goal for each step [Fig. 2]. For this step, 45 minutes is an appropriate amount of time.

Step 5: Set Metrics (KPIs)—qualifying Business Goals

During step 5, the group members will identify action items to move forward utilizing the use cases. In parallel, they discuss key metrics (KPIs) for each use case. KPI examples should be provided by the facilitator to the group members. The selected metrics would be significant indicators of whether the planned business transformation is correctly promoted with the SCP solutions that they would develop. Finally, they will draw one single page as a high-level IoT value roadmap putting all of the insights that they discovered through the steps $1-4$. For example, how to better qualify selected use cases, from which use case should we begin, and what are the "quick wins" or "strategic values." For this step, 30 minutes is an appropriate amount of time.

3.6 Key Achievements of Visioneering Workshop

Through the visioneering session, the following are achieved as group work outcomes recognizing the group members' efforts.

All-hands Intensive Group Presentation 
Regarding the visioneering session, it is most important to recognize its group efforts. The participants intensively work together during the limited session time such as for 120 minutes. At the end of the group session, the group presentation time is required by the facilitator. The aim of this step is that all of the participants at the workshop are able to get a mutual understanding and compare with other group members' outcomes. The presentation time for each group is only 5 minutes. It should include the group CVCA diagram and the high-level SCP value roadmap discussed during the group work (Fig. 2). After the presentation time, the audience (other groups) must ask constructive questions to the presenter group (at least 2 questions). Thus, presentation time provides critical insights regarding the value propositions.

\section{Tailored IoT Value Roadmap with Maturity Curve}

At the end of the group discussion, a value roadmap is crafted as a one-page summary. Figure 1 is an example that is configured with Value Driver, Value Area, Sensing Information, Challenge, Metric, and IoT Solutions.

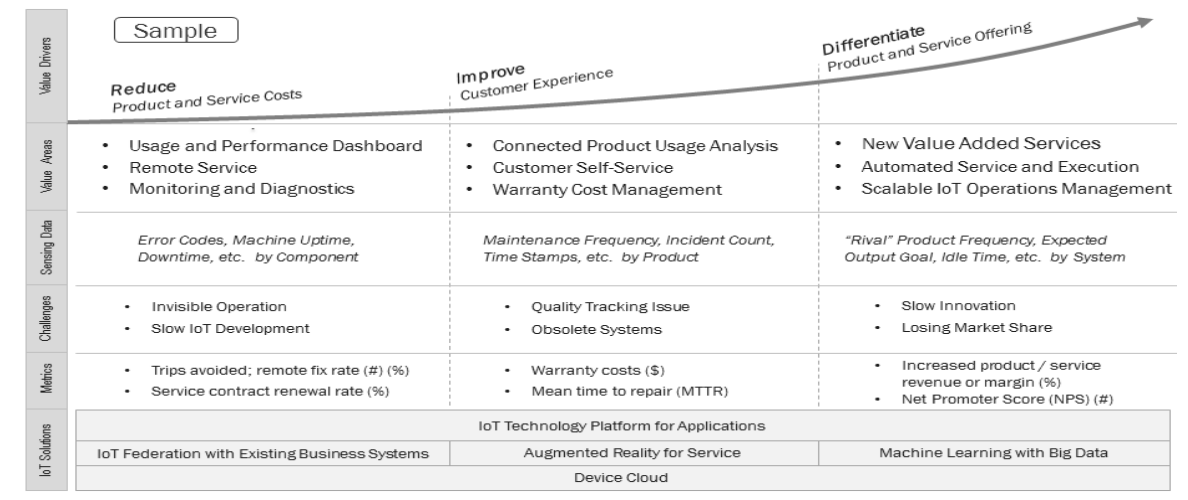

Fig. 2. Tailored IoT Value Roadmap with Maturity Curve (a Sample Template)

\section{Case Study}

\subsection{Background and Opportunity}

Company-X (as anonym) is a leading global manufacturer of specific precision instruments. Company-X's product development process is globally distributed, e.g., among countries A, B, C, and D. For example, the hardware design team is located in country A, whereas the software application development team is located in country B. These teams have been developing high-quality hardware centric products over a period of time, and the company has built a dominant position in the specific global market. The market is quite oligopolistic and has a high entry barrier because of the severe industry-specific regulations. Because the IoT technology is recently recognized as a disruptive innovation that can transform the existing product functionalities, the boundaries of the competition shift and expand from the exiting industry to a broader system of products. Moreover, there was a threat of a severe 
battle for Company-X. This was a new competitive era with not only the existing competitors but also with the newly entering cost-competitive emerging companies.

In such a new business transformation, the senior executive officer in charge of a global business unit in Company-X decided to start a "vision definition" for their future IoT-enabled SCP solutions. This required collaboration with the corporate product management team and the local development members who are distributed among the various countries. A critical challenge was how the differences of cultures and opinions among the members can be efficiently controlled to enable the formulation of a single and common future vision in a short time frame such as a halfday internal big meeting.

This was an opportunity for our study team to propose our developed visioneering workshop framework to the officer, supporting Company-X's vision-making initiative as an independent third party. It was a significant empirical study opportunity for us to examine whether the workshop framework can validate our study concept and its assumption.

\subsection{Characteristic of Participants}

The following distributed members were gathered at a single location in country A (Table 4). They came from four different regions around the world and their nationalities and mother tongues were different. To support mutual communication, a dedicated interpreter staff was assigned for translation between English and the local language of country A.

Table 4. Attendees List of the Visioneering Workshop at Company-X

\begin{tabular}{|c|c|c|c|c|}
\hline Group Name & $\begin{array}{c}\text { Participant } \\
\text { (individual \#) }\end{array}$ & Business title & $\begin{array}{c}\text { Region } \\
\text { (Work location) }\end{array}$ & Mother tongue \\
\hline \multirow{7}{*}{$\begin{array}{l}\text { Group-A } \\
\text { (w/ global } \\
\text { managers) }\end{array}$} & 1 & VP & Americas & language- $a$ \\
\hline & 2 & \multirow{3}{*}{ Director } & EMEA & language- $b$ \\
\hline & 3 & & \multirow{2}{*}{ Americas } & language- $a$ \\
\hline & 4 & & & language- $a$ \\
\hline & 5 & & Asia-Oceania & language-c \\
\hline & 6 & General Mgr. & EMEA & language- $b$ \\
\hline & 7 & Manager & Asia-Oceania & language-c \\
\hline \multirow{4}{*}{$\begin{array}{c}\text { Group-B } \\
\text { (w/ local } \\
\text { managers) }\end{array}$} & 8 & \multirow{4}{*}{ General Mgr. } & \multirow{4}{*}{ Asia-Oceania } & \multirow{4}{*}{ language- $c$} \\
\hline & 9 & & & \\
\hline & 10 & & & \\
\hline & 11 & & & \\
\hline \multirow{4}{*}{$\begin{array}{c}\text { Group-C } \\
\text { (w/local } \\
\text { engineers) }\end{array}$} & 12 & Manager & \multirow{4}{*}{ Asia-Oceania } & \multirow{4}{*}{ language-c } \\
\hline & 13 & \multirow{2}{*}{ Sr. Engineer } & & \\
\hline & 14 & & & \\
\hline & 15 & Engineer & & \\
\hline
\end{tabular}

\subsection{Discussions}

In this paper, we focus our discussion on the "Group Work for Visioneering" session for Round \#4 in Table 2 based on the result for the actual case of Company-X. The 
developed group facilitation approach has comprehensively provided significant insights to the workshop group members. This allowed them to identify IoT values that they have never previously realized. The following three items were particularly significant discussion points.

Well-balanced PLM process as IoT use cases.

The predefined IoT use case templates allowed the group members to provide wellbalanced strategy planning workflow in IoT topics and discussions. Although most of the participants were basically from the "engineering department," they realized the value of selecting some of the IoT initiatives of the product manufacturing and field service processes that were not within their specialties. The initiatives they selected were also well-aligned with the corporate strategy. These potential values would not have been discovered without the use of such templates. In addition, the participants from the "hardware" design team recognized the importance of the value of "software" rather than hardware innovation. Another remarkable contribution by the facilitator was that the 26 use cases were prepared as " 26 cards." This means that the group members enjoyed the group discussion time as if they were playing cards, which had a positive effect by relaxing the participants and enabling them to think about brand new ideas.

\section{Doubling productivity vs. negative busyness?}

During the group work session, the facilitator was rigidly measuring the session time with a stopwatch. This brought about a remarkable increase in productivity. Moreover, the predefined timetable was a quite a useful guide for the facilitator. In fact, there was a very positive endorsement from a lead participant in the workshop, "Without such time management and use case templates, we could not complete on time. We would spend twice as much time as we actually did." On the other hand, the rigid timing also identified some of the participants' mental stress due to the busyness forced by the facilitator. This should be a topic for improvement in a future study.

Multi-linguistic party and challenges on remote facilitation.

Although each group (A, B, and C) comprised people with different backgrounds and cultures from overseas countries, no operationally fatal problems were identified during the group discussion time. All three groups achieved the final conclusions. However, we have to admit the contribution of the professional interpreter's savvy. Such multinational and multi-linguistic group activities are currently estimated to be increasing. We are still dependent on such a talent of the interpreter for better human communication for the solution of the problems involved in the discussion in such a diverse environment. Furthermore, in this case, another facilitator joined remotely through the Web from his base country. Currently, Web meeting applications such as WebEx on a smartphone are very convenient and cheaper than ever before. Thus, we actually applied a remote facilitation style during round \#3 in Table 2 . This had a negative influence because it was quite difficult for the remote facilitator to recognize the audiences' personal perceptions. Generally, it is very important to understand how a remote facilitator can be acceptable in such an unknown situation [2]. This should be improved in the workshop agenda design based on the previous literature and cross-disciplinary studies and research. 


\section{Conclusions and Future Work}

We proposed a visioneering workshop approach utilizing the 26 IoT use cases through the PLM process. We have identified some significant values during the proposed group facilitation approach at a global manufacturing company focused on specifically planning an SCP concept as a part of IoT product solution suite. We also recognized that the proposed approach was acceptable for the workshop participants because they were able to achieve a common vision and consensus on a single SCP concept in a shorter time than they initially estimated. For the workshop participants, the largest contribution was made by the ability to use the comprehensive formatted 26 IoT use case examples. The participants clearly imagined future candidates of IoT solutions because the use cases were pragmatic business templates and were demonstrated in the actual industry environment.

On the other hand, we need to consider the remote facilitator's role at the requirement gathering phase described in the literature [2] as a possibility of virtual meeting space with ICT remote environment. As the next step, we are building on the research of previous studies in directions such as visual planning for virtual multi-site teams [1, 8]. Furthermore, we would like to investigate the effects of adopting innovative user experiences such as augmented reality. This would provide a supportive effect for the globally distributed participants as if they worked together in-person in the same workshop room.

\section{References}

1. Bertilsson, Josefin, Wentzel, G.: Visual Planning. Coordination and Collaboration of Multisite Teams in Product Development Organisations (2015).

2. Damian, Daniela, E., et al.: An Exploratory Study of Facilitation in Distributed Requirements Engineering. Requirements Engineering8.1, 24-26 (2003)

3. Donaldson, Krista, M., Ishii, K., Sheri, D., Sheppard: Customer Value Chain Analysis. Research in Engineering Design16.4, 174-183 (2006)

4. IDC InfoBrief sponsored by PTC: Connected Products and Operation. Reshaping the Manufacturing and Operations Landscape (2015)

5. James, M.:The Internet of Things. Mapping the Value beyond the Hype (2015)

6. Porter, M.E., Heppelmann, J.E.: How Smart, Connected Products are Transforming Companies. Harvard Business Review93.10, 96-114 (2015)

7. Porter, M.E., Heppelmann, J.E.: How Smart, Connected Products are Transforming Competition. Harvard Business Review92.11, 64-88 (2014)

8. Project Visit, http://www.projectvisit.org/ (visited on 10/1/2015)

9. PTC Inc.: IoT Value Roadmap, http://www.ptc.com/File\%20Library/IoT/IoT-Use-CaseeBook.pdf (Visited on 6/10/16)

10. PTC Community, https://www.ptcusercommunity.com/docs/DOC-8646 (visited on 3/19/16)

11. PTC Inc.: To Create Real Business Value You Need to Identify and Prioritize the Specific IoT Use Cases, http://www.ptc.com/internet-of-things/use-cases (visited on 3/1/2016)

12. Stark, J.: PLM and the IoT (\#4): The Opportunities of the IoT. PLM Consultant and Owner, John Stark Associates, https://www.linkedin.com/pulse/plm-iot-4-opportunities-johnstark?trk=mp-reader-card (visited on 1/11/2016)

13. Survey Monkey, https://www.surveymonkey.com/mp/aboutus/ (visited on 3/9/2016) 